\title{
Erratum to: Easy Formation and Dye-Sensitized Solar Cell Application of Highly-Ordered 3D Titania Arrays Using Photodynamic Polymer
}

\section{PilHo Huh and Seong-Cheol Kim}

DOI: $10.1007 / \mathrm{s} 13391-012-1090-6$

On page 133, Figure 2,

: Figure 2B, Figure 2C should be eliminated and Figure 2A should be changed as following Figure.

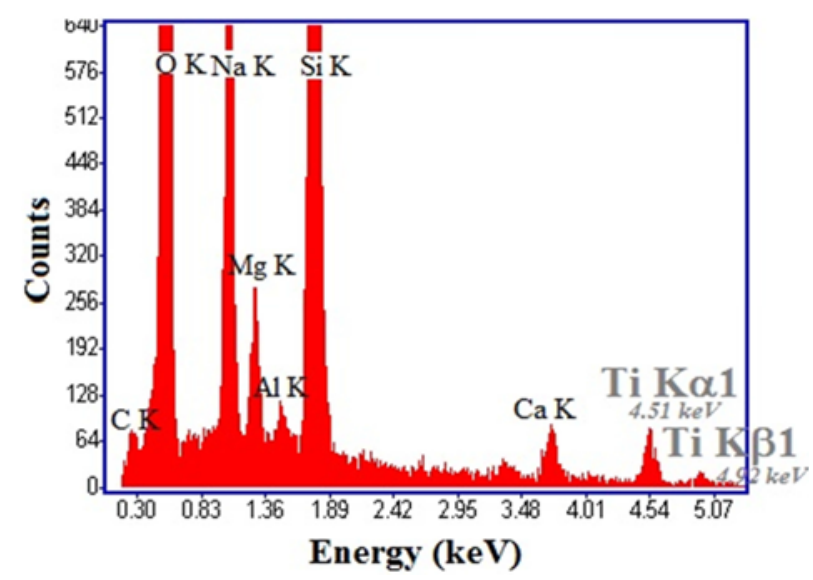

Also Capital A in Figure 2A should be eliminated and the Caption of Figure 2 should be changed as: Fig. 2. EDAX spectrum of $\mathrm{TiO}_{2}$ nanostructures formed on an FTO glass substrate.

On page 132, middle paragraph, on the right,

: Middle paragraph should be replaced with following text

The EDAX spectrum of nanostructured $\mathrm{TiO}_{2}$ arrays is shown in Figure 2. The presence of $\mathrm{Ti}$ in the nanostrucures after heat-treatment was confirmed by the presence of the Ti $\mathrm{K}_{\alpha 1}$ and Ti $\mathrm{K}_{\beta 1}$ peaks at $4.51 \mathrm{keV}$ and $4.92 \mathrm{keV}$. A very weak $\mathrm{C} \mathrm{K}_{\alpha}(0.282 \mathrm{keV})$ line is observed in comparison to that of the non-heat-treated sample. The finding indicates that $\mathrm{TiO}_{2}$ nanostructures were created with the removal of the polymeric SRG templates. Furthermore, anatase phase of $\mathrm{TiO}_{2}$ nanoparticles was confirmed by the XRD pattern of $2 \theta=25.2^{\circ}$ with d-spacing of $3.53 \AA$ and Raman peaks observed at 402,518 , and $640 \mathrm{~cm}^{-1}$. 